\title{
Impact of International Cross-Listing and Delisting on Return Volatility*
}

\author{
Lin Cong \\ University of Chicago Booth School of Business, USA
}

Copyright 2017 by authors, all rights reserved. Authors agree that this article remains permanently

open access under the terms of the Creative Commons Attribution License 4.0 International License

\begin{abstract}
This paper studies the effects of international cross-listing and delisting on the overall daily volatility, nontrading-hour volatility and trading-hour volatility of stock returns, with a focus on the U.S. firms cross-listed/delisted on the Tokyo Stock Exchange. We find that international cross-listing (delisting) reduces (increases) overall and trading-hour volatility while keeps non-trading-hour volatility unaffected. The findings are consistent with the hypothesis that international cross-listing (delisting) reduces (increases) the amount of private information and non-informed speculations.
\end{abstract}

Keywords Cross-Listing, Cross-Delisting, Return Volatility

JEL: G12, G15

\section{Introduction}

International stock cross-listing has drawn people's attention for quite a long time. Besides being traded domestically, some firms also decide to list themselves in abroad stock exchanges. Whether this action is value creation or reduction and how it will affect stock prices have been hotly debated. (See Foerster and Karolyi [9], King and Segal [13], and Roosenboom and van Dijk [16] for instances) But less attention is paid to how cross-listing will affect stock return's domestic volatility.

Among exceptions, Howe and Madura [11], and Howe, Madura, and Tucker [12] examine the impact of international listing on risk, and conclude that international listing increases anticipated volatility. Using Tokyo Stock Exchange data, Barclay, Litzenberger, and Warner [3] arguet hat international cross-listing does neither affect the overall level of variance nor its overnight pattern, but does increase the vo-

\footnotetext{
* The paper was mostly completed while the author is at Stanford University Graduate School of Business. The author thanks Fan Zhang and the anonymous referee for detailed feedback and comments, and Yiran Fan for excellent research assistance.
}

latility in trading hours. Domowitz, Glen, and Madhavan [8] contend the traditional dichotomy between market integration and fragmentation and examine both volatility and liquidity changes due to international cross-listing by comparing Mexican domestic stocks and their American Depositary Receipts. Bayar and Önder [4] use a similar approach to study liquidity and price volatilities of cross-listed French stocks and provide evidence for the lack of market integration between French and German markets.

However, results are mixed in the existing literature. For instance, Barclay, Litzenberger, and Warner [3] conclude that international cross-listing leaves the overall and overnight volatility unaffected, but Bayar and Önder [4] argue that both volatilities will increase. One possible explanation for the difference is that the empirical methodology they use differs. Specifically, Barclay, Litzenberger, and Warner [3] exploit non-parametric $\mathrm{T}$ tests to compare the volatility before and after cross-listing. They involve non cross-listed comparables for each cross-listed firms in order to control for macro and industry effects. But by taking non-parametric $\mathrm{T}$ tests, they can hardly control for firm fixed effects. On the contrary, Bayar and Önder [4] conduct a model-based analysis for each cross-listed firm in their sample in order to control for the firm fixed effects. But they do not include non crosslisted comparables, which means that they can hardly control for other, say, industry and macro effects.

Moreover, little literature has focused on the effects of cross-delisting on volatility, although it is natural to examine if cross-delisting just has the opposite effects as cross-listing.

In this paper, we investigate both impacts of international cross-listing and cross-delisting on volatility with more robust methodology. We conduct a model-based analysis with both non cross-listing comparables and firm fixed effects to examine how the overall volatility, trading volatility and nontrading volatility of stock returns will change before and after the stock traded in United States is cross-listed or delisted in the Tokyo Stock Exchange. The overall volatility, trading volatility and non-trading volatility are defined as the daily 
close price-to-close price (hereafter close-to-close) volatility, open price-to-close price (hereafter open-to-close) volatility and close price-to-open price (hereafter close-to-open) volatility respectively. Notice that due to the time difference, the Tokyo Stock Exchange opens (closes) when the American market is closed (open). Hence, trading volatility covers the period when the American market is open while the Japanese market is closed; non-trading volatility covers the period when the American market is closed while the Japanese market is open.

French and Roll [10] propose three hypotheses on how return volatility arises. First, the public information hypothesis states that public information such as corporate announcements or macroeconomic news induces the observed return volatility in case. If international cross-listing and crossdelisting do not change the release pattern of public information, then there should be little change in return volatility due to cross-listing or delisting. For instance, one may believe that a U.S. firm will normally release information in U.S business hours, no matter if it is listed in Japan. As a result, its volatility will not be significantly affected via the public information channel after it is listed in Japan.

Second, the private information hypothesis states that private information can only be incorporated via trading and this generates the observed daily volatility patterns. In the Kyle [14] model, volatility is induced by trading volume instead of the length of trading hours. If this argument is true, then there would be little direct effects of cross-listing and delisting on volatility (an indirect channel may be through trading volume). In models where incorporation of private information is related to the length of trading-hours (for example, informed traders arrive stochastically during the day), however, volatility may change before and after cross-listing and delisting, especially if the incorporation of information takes place uniformed throughout trading-hours in both the domestic market and the foreign market. In this case, cross-listing (delisting) may induce more (less) private information discovery that leads to greater volatility.

But alas, not all trading hours are created equal. Barclay, Litzenberger, and Warner [3] argue that informed traders will not shift their trading abroad. Liquidity traders tend to focus on domestic market where the transaction costs tend to be lower. In Admati and Pfleiderer [1] setting, the discretionary liquidity traders then prefer to cluster their trades in domestic market. The informed traders follow suit and there will be few informed traders active in the foreign market. As such the extended trading hours will not make a big difference and under the private information hypothesis, international crosslisting and delisting will have little impact on stock return volatility. The work of Chowdhry and Nanda [5] on the existence of dominant markets supports this view.

However, the international cross-listing may just reduce the amount of private information. As documented in Stulz [17], Coffee [6], Coffee [7], and King and Segal [13], crosslisting makes the firm bonding itself to a new jurisdiction sy- stem and increasing regulation. It is then naturally to assume that firms will take actions, say, conducting more stringent confidential treatment, or reducing the amount of private information available after cross-listing. If it were the case, then the trading volatility should decrease since less private information can be incorporated, while non-trading volatility may stay roughly unaffected. Similarly, cross-delisting may induce firms to loose its confidential treatment. Thus more private information may be incorporated during the trading hours so that the trading volatility should increase.

The third hypothesis is that noisy trading induces volatility. Though French and Roll [10] do not think noisy trading explains their results well, many subsequent work has extended this concept further. However, how international cross-listing and delisting will affect noisy trading is ambiguous. Barclay, Litzenberger, and Warner [3] divide noisy trading into two categories: the one that related to trading time (henceforth referred to as trading-hour-related), and the one that related to trading volume (henceforth referred to as volume-related). Since the foreign market usually has small capitalization and volume, they argue that the volume-related noise would have little change before and after cross-listing and delisting. On the other hand, trading-hour-related noise may increase (decrease) after cross-listing (delisting) due to longer (shorter) trading hours. This hypothesis will then predict that the nontrading volatility will increase (decrease) with cross-listing (delisting) but the trading volatility should be little influenced.

Besides, Merton [15] and King and Segal [13] argue that cross-listing will draw more investors' attention to the stock. With more investors' recognition, it might be harder for the stock to largely deviate from its fundamental. This would reduce non-informed speculations and thus reducing noisy trading in trading hours but leave the non-trading volatility roughly unchanged. Delisting would have the corresponding opposite effects.

We study 20 cases where U.S. firms cross-listing and delisting in the Tokyo Stock Exchange. We find that cross-listing (delisting) reduces (increases) overall and trading-hour volatility while leaves non-trading-hour volatility unaffected. The findings can be explained by the hypothesis that international cross-listing (delisting) reduces (increases) the amount of private information, or by the hypothesis that international cross-listing (delisting) reduces (increases) the amount of non-informed speculations. Both have been analyzed above.

The reminder of the paper is organized as follow. Section 2 describes the data and methodology, followed by Section 3 presenting the empirical results for both cross-listing and delisting. Section 4 concludes. 
Table 1. Companies Cross-listed/delisted in Tokyo Stock Exchange

\begin{tabular}{cccccc}
\hline \hline & & & Panel A: Listing Events & & \\
\hline No. & Listing Code & Company & Cross-listing Date & Control Code & Control Company \\
\hline 1 & AIG & American International Group, Inc & $9 / 18 / 1987$ & AFG & American Financial Group \\
2 & AAPL & Apple Inc & $9 / 18 / 1990$ & MSFT & Microsoft Corp \\
3 & AXP & American Express Compnay & $11 / 14 / 1985$ & BAC & Bank of Amerca Corp \\
4 & T & AT\&T & $11 / 20 / 1987$ & VZ & Verizon Communications \\
5 & BA & Boeing Company & $10 / 5 / 1990$ & NOC & Northrop Grumman Corp \\
6 & 2245Q & Borden Company & $8 / 25 / 1987$ & DOW & Dow Chemical Company \\
7 & LLY & Eli Lilly \& Co. & $11 / 21 / 1986$ & PFE & Pfizer Inc \\
8 & XOM & Exxon Mobile & $12 / 16 / 1986$ & BP & BP p.l.c \\
9 & F & Ford Motor Company & $9 / 20 / 1988$ & TM & Toyota Motor Corp \\
10 & GE & General Electric & $11 / 10 / 1987$ & UTX & United Techonologies Corp \\
11 & LNC & Lincoln National Corp & $12 / 15 / 1987$ & ANAT & American National Insurance Company \\
12 & MCD & McDonald's Corp & $7 / 3 / 1986$ & WEN & Wendy's Arby's Group Inc \\
13 & MER & Merrill Lynch & $11 / 18 / 1986$ & BAC & Bank of Amerca Corp \\
14 & OXY & Occidental Petroleum Corp & $12 / 18 / 1987$ & DD & E.I du Pont de Nemours \& Company \\
15 & PEP & PesiCo, Inc & $11 / 13 / 1989$ & KO & Coca-cola Company \\
16 & PPG & PPG Industries, Inc & $9 / 4 / 1987$ & SHW & Sherwin-Williams Company \\
17 & PG & Procter \& Gamble Company & $5 / 30 / 1986$ & JNJ & Johnson \& Johnson \\
18 & 1513Q & Rockwell Interantaional Corp & $11 / 30 / 1987$ & EMR & Emerson Electric Co. \\
19 & TXN & Texas Instruments Inc & $11 / 10 / 1989$ & ADI & Analog Devices, Inc. \\
20 & DIS & Walt Dsiney Company & $6 / 27 / 1988$ & CMCSA & Comcast Corp \\
\hline \hline
\end{tabular}

\begin{tabular}{|c|c|c|c|c|c|}
\hline \multicolumn{6}{|c|}{ Panel B: Delisting Events } \\
\hline No. & Listing Code & Company & Delisting Date & Control Code & Control Company \\
\hline 1 & AXP & American Express Compnay & $6 / 30 / 1995$ & BAC & Bank of Amerca Corp \\
\hline 2 & AAPL & Apple Inc & $12 / 24 / 2004$ & MSFT & Microsoft Corp \\
\hline 3 & $\mathrm{~T}$ & AT\&T & $6 / 27 / 1997$ & $\mathrm{VZ}$ & Verizon Communications \\
\hline 4 & LLY & Eli Lilly \& Co. & $4 / 16 / 2003$ & PFE & Pfizer Inc \\
\hline 5 & XOM & Exxon Mobile & $12 / 26 / 1996$ & BP & BP p.l.c \\
\hline 6 & $\mathrm{~F}$ & Ford Motor Company & $6 / 30 / 1995$ & TM & Toyota Motor Corp \\
\hline 7 & NEE & NextEra Energy Inc & $12 / 30 / 1992$ & DUK & Duke Energy Corp \\
\hline 8 & GE & General Electric & $6 / 30 / 1995$ & UTX & United Techonologies Corp \\
\hline 9 & GT & Goodyear Tire \& Rubber Co. & $6 / 30 / 1994$ & CTB & Cooper Tire \& Rubber Co. \\
\hline 10 & IBM & International Business Machines Corp & $5 / 2 / 2005$ & HPQ & Hewlett-Packard Co. \\
\hline 11 & ITT & ITT Corporation & $3 / 31 / 1994$ & RTN & Paytheon Company \\
\hline 12 & EKDKQ & Eastman Kodak Company & $6 / 30 / 1994$ & CAJ & Canon Inc \\
\hline 13 & LNC & Lincoln National Corp & $6 / 10 / 1998$ & ANAT & American National Insurance Company \\
\hline 14 & MCD & McDonald's Corp & $5 / 19 / 1999$ & WEN & Wendy's Arby's Group Inc \\
\hline 15 & 210967Q & Nynex Corp & 2/1/1994 & WDC & Western Digital Corp. \\
\hline 16 & OXY & Occidental Petroleum Corp & $4 / 28 / 1998$ & DD & E.I du Pont de Nemours \& Company \\
\hline 17 & PPG & PPG Industries, Inc & $2 / 28 / 1995$ & SHW & Sherwin-Williams Company \\
\hline 18 & PG & Procter \& Gamble Company & $5 / 6 / 2004$ & $\mathrm{JNJ}$ & Johnson \& Johnson \\
\hline 19 & $\mathrm{TXN}$ & Texas Instruments Inc & 9/28/1997 & ADI & Analog Devices, Inc. \\
\hline 20 & DIS & Walt Dsiney Company & 2/13/1996 & CMCSA & Comcast Corp \\
\hline
\end{tabular}

\section{Data and Methodology}

\subsection{Data}

All data used in this paper is from Bloomberg. A list of listing and delisting on Tokyo Stock Exchange can be found at http://www.tse.or.jp/english/listing/foreign/frhistorye.pdf.

We obtain data for 20 U.S. firms that were cross-listing on the Tokyo Stock Exchange at some point of time, and another 20 U.S. firms that were delisted from the Tokyo Stock Exchange at some point of time. For each firm cross-listing or delisting, we find a comparable control firm. We follow, in order of preference, Yahoo Finance suggested major competitors, Google Finance related companies, and firms in related industries. To be a control firm, it should not be crosslisted or delisted during the six-year window we look at, or the cross-listing or delisting dates should be more than two years away from the corresponding dates of the firm we are examining. The delisting should not be due to mergers or other fundamental structural changes of the firm. A list of firms and their control counterparts for our cross-listing and delisting study can be found in Table 1 .

We obtain the daily open and close prices for both the treatment firms and the control firms. For each cross-listing and delisting event, we cover a span of six years (three years before and three years after listing or delisting) to detect long-term effects. Bayar and Önder [4] cover around 500 days surrounding the event dates, while Angelidis, Koulakiotis, Lyroudi, and Tolikas [2] cover 20 days. There is nothing inherently wrong with shorter window. But we argue that the return could be highly volatile around the event dates, and we have to examine persistent changes rather than transitory changes to see if cross-listing and delisting effects on volatility come from the change in information release pattern, information incorporation, or noisy trading. 
Table 2. Summary Statistics

This table reports the summary statistics. Overall Var is defined as the square of daily close-to-close return. Trading Var is defined as the square of daily open-to-close return. Non-trading Var is defined as the square of daily close-to-open return. Panel A is for cross-listing events while Panel B is for cross-delisting events. In each panel, the number of observations, sample mean, standard deviation, the minimum and maximum are reported.

\begin{tabular}{lccccc}
\hline \hline & \multicolumn{2}{c}{ Panel A: Cross-listing } & & \\
\hline & count & mean & sd & min & max \\
\hline Overall Var & 19840 & .0002034 & .0002746 & 0 & .001355 \\
Trading Var & 19779 & .0001634 & .0002226 & 0 & .0011058 \\
Non-trading Var & 19761 & .0000337 & .0000527 & 0 & .0003033 \\
Overall Var (Control) & 19840 & .00022 & .0003295 & 0 & .001837 \\
Trading Var (Control) & 19791 & .0001732 & .0002671 & 0 & .0015747 \\
Non-trading Var (Control) & 19773 & .0000513 & .0000888 & 0 & .0005606 \\
\hline \hline & \multicolumn{7}{c}{} \\
& Panel B: Cross-delisting & & & \\
\hline Count & mean & sd & min & max \\
\hline Overall Var & 19840 & .000167 & .0002341 & 0 & .0012 \\
Trading Var & 19859 & .0001372 & .000189 & 0 & .0009381 \\
Non-trading Var & 19840 & .0000276 & .0000442 & 0 & .0002474 \\
Overall Var (Control) & 19840 & .0001913 & .0002831 & 0 & .0014793 \\
Trading Var (Control) & 19857 & .0001495 & .0002324 & 0 & .0012373 \\
Non-trading Var (Control) & 19841 & .0000437 & .0000723 & 0 & .0004 \\
\hline \hline
\end{tabular}

Table 3. Daily Volatility before and after International Cross-listing

This table reports the two-sample T test results that compare the variance before and after cross-listing. Panel A, B, C are for the overall variance, trading variance, and non-trading variance respectively as defined in Table 2 . In each panel, we report the pooled results in column (1) and separate results for different day of week in following columns. T statistics are in parentheses and $*, * *, * * *$ indicate significance at $10 \%, 5 \%$, and $1 \%$ level respectively.

\begin{tabular}{|c|c|c|c|c|c|c|}
\hline \multicolumn{7}{|c|}{ Panel A: Overall Variance } \\
\hline & (1) & (2) & (3) & (4) & (5) & (6) \\
\hline & All & Mon & Tue & Wed & Thr & Fri \\
\hline \multirow[t]{2}{*}{ Before-After } & $0.0000146^{* * *}$ & 0.00000687 & $0.0000244 * * *$ & $0.0000152^{*}$ & $0.0000249^{* * *}$ & 0.000000849 \\
\hline & $(3.74)$ & $(0.76)$ & $(2.84)$ & $(1.78)$ & $(2.93)$ & $(0.10)$ \\
\hline$N$ & 19840 & 3766 & 4066 & 4093 & 3972 & 3943 \\
\hline \multicolumn{7}{|c|}{ Panel B: Trading Variance } \\
\hline & (1) & (2) & (3) & (4) & (5) & (6) \\
\hline & All & Mon & Tue & Wed & Thr & Fri \\
\hline \multirow{2}{*}{ Before-After } & $0.0000162^{* * *}$ & 0.0000103 & $0.0000299 * * *$ & 0.00000772 & $0.0000207 * * *$ & 0.0000117 \\
\hline & $(5.11)$ & $(1.37)$ & $(4.28)$ & (1.11) & $(3.05)$ & $(1.64)$ \\
\hline \multirow[t]{4}{*}{$N$} & 19779 & 3783 & 4068 & 4046 & 3964 & 3918 \\
\hline & \multicolumn{6}{|c|}{ Panel C: Non-trading Variance } \\
\hline & (1) & (2) & (3) & (4) & (5) & (6) \\
\hline & All & Mon & Tue & Wed & Thr & Fri \\
\hline \multirow[t]{2}{*}{ Before-After } & $-0.00000440^{* * *}$ & $-0.00000346^{*}$ & $-0.00000548^{* * *}$ & -0.00000206 & $-0.00000426^{* * *}$ & $-0.00000685^{* * *}$ \\
\hline & $(-5.88)$ & $(-1.91)$ & $(-3.28)$ & $(-1.27)$ & $(-2.62)$ & $(-4.16)$ \\
\hline$N$ & 19761 & 3716 & 4054 & 4105 & 3960 & 3926 \\
\hline
\end{tabular}


Table 4. Daily Excess Volatility before and after International Cross-listing

This table reports the two-sample T test results that compare the excess variance (compared with the comparable) before and after cross-listing. Panel A, B, C are for the overall variance, trading variance, and non-trading variance respectively as defined in Table 2. In each panel, we report the pooled results in column (1) and separate results for different day of week in following columns. T statistics are in parentheses and *,**, *** indicate significance at $10 \%, 5 \%$, and $1 \%$ level respectively.

\begin{tabular}{|c|c|c|c|c|c|c|}
\hline \multicolumn{7}{|c|}{ Panel A: Overall Volatility } \\
\hline & (1) & (2) & (3) & (4) & (5) & (6) \\
\hline & All & Mon & Tue & Wed & Thr & Fri \\
\hline \multirow[t]{2}{*}{ Before-After } & $0.0000258^{* * *}$ & $0.0000345 * * *$ & $0.0000269 * *$ & $0.0000326^{* * *}$ & $0.0000328^{* * *}$ & 0.00000231 \\
\hline & $(4.55)$ & $(2.60)$ & $(2.13)$ & $(2.63)$ & $(2.60)$ & $(0.18)$ \\
\hline \multirow[t]{4}{*}{$N$} & 19004 & 3608 & 3910 & 3915 & 3809 & 3762 \\
\hline & \multicolumn{6}{|c|}{ Panel B: Trading Volatility } \\
\hline & (1) & (2) & (3) & (4) & (5) & (6) \\
\hline & All & Mon & Tue & Wed & Thr & Fri \\
\hline \multirow[t]{2}{*}{ Before-After } & $0.0000343^{* * *}$ & $0.0000351^{* * *}$ & $0.0000399 * * *$ & $0.0000410^{* * *}$ & $0.0000305 * * *$ & $0.0000244^{* *}$ \\
\hline & $(7.38)$ & $(3.27)$ & $(3.86)$ & $(4.10)$ & $(2.93)$ & $(2.32)$ \\
\hline \multirow[t]{4}{*}{$N$} & 18905 & 3609 & 3894 & 3868 & 3791 & 3743 \\
\hline & \multicolumn{6}{|c|}{ Panel C: Non-trading Volatility } \\
\hline & (1) & (2) & (3) & (4) & (5) & (6) \\
\hline & All & Mon & Tue & Wed & Thr & Fri \\
\hline \multirow[t]{2}{*}{ Before-After } & $0.00000882 * * *$ & $0.0000124 * * *$ & $0.00000627^{* *}$ & $0.00000785^{* * *}$ & $0.00000942 * * *$ & $0.00000851^{* * *}$ \\
\hline & $(6.34)$ & $(3.67)$ & $(2.04)$ & $(2.61)$ & $(3.08)$ & $(2.79)$ \\
\hline$N$ & 18915 & 3530 & 3897 & 3919 & 3798 & 3771 \\
\hline
\end{tabular}

We notice that in the literature, the square of daily price changes, $\left(\Delta P_{t}\right)^{2}$, is often used as the proxy for unobserved price variance (Domowitz, Glen, and Madhavan [8], Bayar and Önder [4]). The rationale is that if the number of traders is large, the cumulative price changes are approximately normal, and the expected absolute daily price change is related to the variance of daily price changes in a direct way. However this relies on an assumption that price movement roughly follows a random walk which is problematic. We argue that price change is not fundamental and could be highly unstable. For example, a stock trading at low price is likely to have smaller price volatility compared to a stock trading at high price, thus we argue that it might be better to look at return volatility or log return volatility, in order to perform quantitative analysis. Stock return volatility is more fundamental also in the sense that the price volatility will be different in the case where we view two shares as a single entity from the case where we view them as two separate entities, but as an investor this should not matter because she only cares about return. Return volatility would be a more natural subject to study. We then use the square of net returns as proxies for unobservable return variances.

We calculate three types of return variance: overall variance, which is defined as the square of close-to-close net return, trading variance, which is defined as the square of opento-close net return, and non-trading variance, which is defined as the square of close-to-open net return. While French and Roll [10] in their classical analysis define the concept of hourly volatility, we recognize that there are significant heterogeneity among the trading and non-trading hours (the Ushape in intra-day trading causes high volatility around open and close hours, weekends non-trading hour volatility is sufficiently different from weekday nights non-trading volatility as the frequency of public news is different, etc), so defining hourly volatility would not help much in giving intuitions. As such, we just use our broadly defined trading and nontrading variance. We are not only examining their absolute levels, but also comparing the levels before and after crosslisting/delisting relative to some control stocks to get rid of the changes caused by other macroeconomic factors and time trends. It is true that open-to-close and close-to-open do not fully capture the trading and non-trading variance due to the fact that volumes and variance shoot up around openning and closing times of the markets (Admati and Pfleiderer [1]), they nonetheless capture the essence of the variance that we want to look at.

We drop daily close-to-close, open-to-close and close-toopen returns that are higher than the $95 \%$ corresponding percentile. Table 2 shows the summary statistics. It can be seen that in both panels, non-trading variance is much more smaller than trading variance, which is consistent with French and Roll [10]. 


\subsection{Methodology}

We compute the equally weighted average of return variance. It could be argued we should use some other better weighting scheme such as value-weighted average. However due to the limited availability on market capitalization data, we argue equal-weighted average would be a natural choice. Moreover, since we are looking at return volatility instead of price volatility, it is not a bad idea to treat different stocks on equal footing as they are all investment options to a potential investor.

We start with simple two-sample $\mathrm{T}$ test to determine if there are any evidence of changes in return variance before and after cross-listing and delisting. We do this for each day of the week, as the non-trading hours from Friday night to Monday morning is much longer than any other days' nontrading hours. Specifically, Monday's non-trading variance is the Friday close to Monday open variance; Tuesday's nontrading variance is the Monday close to Tuesday open variance, so on so forth.

We then calculate the excess variance, which is defined as the difference between the return variance of the firm experiencing cross-listing/delisting and that of the control firm. We repeat the above two sample $\mathrm{T}$ test for overall, nontrading and trading excess variances, in order to control for the size, cash flow, business activities, etc.

We also conduct a model based analysis, where we can control the comparable firm's return variance, firm fixed effect and day of week fixed effect explicitly. Specifically, we use a model in the same spirit as that developed by Domowitz, Glen, and Madhavan [8], and Bayar and Önder [4], but we control for the firm fixed effect, the day of the week, and use variance of comparable firms in the same industry (according to competitors criteria on Yahoo Finance and Google Finance) as control variables instead of the market variance. While existing literature mostly uses the volatility of market index or sector index as controls, using the variance of returns of a firm that has comparable size, cash flow, business activities, etc, would provide better control because the latter captures the movements in volatility due to non-crosslisting/delisting factors that are specific to the firm in question. Different from Domowitz, Glen, and Madhavan [8], or Bayar and Önder [4], we allow possible changes on the coefficient of return variance of the control firm before and after the treatment.

Specifically, for the overall variance, we specify

$$
\begin{array}{r}
R_{i, t}^{2}=\beta_{0}+\beta_{1} D_{i, t}+\beta_{2} R_{i, t-1}^{2} D_{i, t}+\beta_{3} I_{i, t}^{2}+\beta_{4} I_{i, t}^{2} D_{i, t} \\
+\alpha_{i}+\gamma_{t}+\eta_{i, t},
\end{array}
$$

where $R_{i, t}$ is the close-to-close return for firm $i$ at day $t$ (the cross-listing or delisting day is defined as day 0 ), $D_{i, t}$ is the indicator of cross-listing or delisting. $I_{i, t}$ is the close-toclose return of the comparable firm for firm $i$ at day $t, \alpha_{i}$ is the firm fixed effect, $\gamma_{t}$ is the day of week fixed effect and $\eta_{i, t}$ is the error term. Standard errors are clustered at firm level $i$.

For the trading and non-trading return variance, we use the following,

$$
\begin{gathered}
T R_{i, t}^{2}=\beta_{0}+\beta_{1} D_{i, t}+\beta_{2} T R_{i, t-1}^{2} D_{i, t}+\beta_{3} N R_{i, t}^{2}+ \\
\beta_{4} N R_{i, t}^{2} D_{i, t}+\beta_{5} T I_{i, t}^{2}+\beta_{6} T I_{i, t}^{2} D_{i, t}+\alpha_{i}+\gamma_{t}+\eta_{i, t}, \\
N R_{i, t}^{2}=\beta_{0}+\beta_{1} D_{i, t}+\beta_{2} N R_{i, t-1}^{2} D_{i, t}+\beta_{3} T R_{i, t-1}^{2}+ \\
\beta_{4} T R_{i, t-1}^{2} D_{i, t}+\beta_{5} N I_{i, t}^{2}+\beta_{6} N I_{i, t}^{2} D_{i, t}+\alpha_{i}+\gamma_{t}+\eta_{i, t},
\end{gathered}
$$

where $T R_{i, t}$ is the open-to-close return for firm $i$ at day $t$, $N R_{i, t}$ is the t- 1 close-to-t open return for firm $i, T I_{i, t}$ is the open-to-close return of the comparable firm for firm $i$ at day $t$, and $N I_{i, t}$ is the $\mathrm{t}-1$ close-to-t open return of the comparable firm for firm $i$. All other variables are defined as in (1). Standard errors are clustered at firm level $i$.

\section{Empirical Results}

\subsection{International Cross-listing}

Table 3 shows the simple two sample T test results. It can be seen from Panel A Column (1) that the overall variance before cross-listing is significantly higher than the overall variance after cross-listing, which indicates that cross-listing helps to reduce the overall variance. Specifically, the average overall variance before cross-listing is 0.0002107 (or equivalently $\sqrt{0.0002107 \times 252}=23.04 \%$ annual volatility) and it declines to 0.0001961 (or equivalently $22.23 \%$ annual volatility) after cross-listing, indicating a $6.9 \%$ reduction. Besides, this effect is mainly driven by days in the middle of a week. Moreover, Panel B shows that the trading variance is also significantly decreased by cross-listing. It experiences a considerable $9.4 \%$ decline from 0.0001715 (or equivalently $20.79 \%$ annual volatility) before to 0.0001553 (or equivalently $19.78 \%$ annual volatility) after. Tuesday and Thursday seem to be the driving days in a week. Lastly, Panel C seems to indicate an increase in non-trading variance. And it seems to be quite consistent across most days of a week.

One may notice that all of our listing events shown in Table 1 happened in the late 1980s. There might be some macroeconomic factors that made all stocks' volatilities increase in the late 1980s compared with those in the early 1980s, which may drive the phenomenon observed in Table 1. To address that, we calculate the excess variance of each cross-listing firm net from its comparable firm. The comparable firm has similar size and business as the cross-listing firm. Thus, if there were some macroeconomic factors that drived up the variance, it should also affect the comparable firm's variance.

It can be seen from Table 4 that cross-listing reduces the excess overall variance and trading variance, which is similar 
to what is observed in Table 3. Moreover, the effect seems to be more robust across most days in a week. However surprisingly, using the excess terms, cross-listing seems to decrease the non-trading variance instead of increasing it as shown in Table 3 . The flipping sign in non-trading variance, as well as other results shown in Table 3 and 4, might be due to the fact that non-parametric analysis can hardly control for the firm fixed effect. There might be some firm idiosyncratic character that drives the results.

In order to deal with that, we run the regression as specified in (1), (2) and (3) with firm fixed effects. We also control for the variance of comparable firms and the day of week fixed effects. Results regarding the overall variance are shown in Table 5. Column (1) indicates that after controlling for the comparable firm, lag one day variance, and firm fixed effects, the level of the overall variance decreases significantly after cross-listing, which is equivalent to a $\sqrt{0.0000226 \times 252}=$ $7.53 \%$ reduction in annual volatility.

Table 5. Cross-listing: Overall Variance

This table reports the regression results for overall variance before and after cross-listing. $D$ is the indicator for experiencing a cross-listing. Overall variance is defined in Table 2. T statistics are in parentheses and *, **, *** indicate significance at $10 \%, 5 \%$, and $1 \%$ level respectively.

\begin{tabular}{lcc}
\hline \hline & $(1)$ & $(2)$ \\
& Overall variance & Overall variance \\
\hline $\mathrm{D}$ & $-0.0000225^{* *}$ & $-0.0000226^{* *}$ \\
& $(-2.04)$ & $(-2.04)$ \\
Lag Overall Var & $0.0532^{* * *}$ & $0.0533^{* * *}$ \\
& $(5.87)$ & $(5.92)$ \\
D*Lag Overall Var & -0.0104 & -0.0104 \\
& $(-0.68)$ & $(-0.68)$ \\
Overall Var (Control) & $0.0876^{* * *}$ & $0.0875^{* * *}$ \\
& $(4.70)$ & $(4.72)$ \\
D*Overall Var (Control) & $0.0352^{* *}$ & $0.0353^{*}$ \\
& $(1.82)$ & $(1.84)$ \\
Firm Fixed Effects & Yes & Yes \\
Day of Week Fixed Effects & No & Yes \\
Constant & & \\
& $0.000175^{* * *}$ & $0.000175^{* * *}$ \\
\hline Observations & $(25.28)$ & $(21.14)$ \\
\hline \hline
\end{tabular}

The lag overall variance is significant in explaining today's overall variance, indicating some persistence in the variance process. More interestingly, cross-listing has litter impact on this persistence structure, as the intersection term is not significant. Lastly, adding day of week controls has little impact on the estimates, as shown in column (2) Table 5.

Table 6 shows that cross-listing also causes the trading variance to decrease considerably, by an equivalent magnitude of $\sqrt{0.0000212 \times 252}=7.31 \%$ per annum. The significant positive coefficient on the lag term also implies the persistence of trading volatility. But again, this persistency structure seems to be little affected by cross-listing due to the insignificance on the intersection term.

Table 6. Cross-listing: Trading Variance

This table reports the regression results for trading variance before and after cross-listing. $D$ is the indicator for experiencing a cross-listing. Trading variance is as defined in Table 2. T statistics are in parentheses and *,**,*** indicate significance at $10 \%, 5 \%$, and $1 \%$ level respectively.

\begin{tabular}{|c|c|c|}
\hline & $\begin{array}{c}(1) \\
\text { Trading variance }\end{array}$ & $\begin{array}{c}(2) \\
\text { Trading variance }\end{array}$ \\
\hline $\mathrm{D}$ & $\begin{array}{c}-0.0000212^{* *} \\
(-2.22)\end{array}$ & $\begin{array}{c}-0.0000212^{* *} \\
(-2.22)\end{array}$ \\
\hline Lag Trading Var & $\begin{array}{c}0.0487 * * * \\
(4.78)\end{array}$ & $\begin{array}{c}0.0488^{* * * *} \\
\quad(4.78)\end{array}$ \\
\hline D*Lag Trading Var & $\begin{array}{l}-0.0166 \\
(-1.05)\end{array}$ & $\begin{array}{l}-0.0166 \\
(-1.05)\end{array}$ \\
\hline Non-trading Var & $\begin{array}{r}0.126^{*} \\
(1.83)\end{array}$ & $\begin{array}{r}0.125^{*} \\
(1.81)\end{array}$ \\
\hline D*Non-trading Var & $\begin{array}{l}-0.0224 \\
(-0.30)\end{array}$ & $\begin{array}{r}-0.0230 \\
(-0.30)\end{array}$ \\
\hline Trading Var (Control) & $\begin{array}{c}0.0814^{* * * *} \\
\quad(3.78)\end{array}$ & $\begin{array}{l}0.0815^{* * * *} \\
\quad(3.76)\end{array}$ \\
\hline D*Trading Var (Control) & $\begin{array}{c}0.0238 \\
(1.39)\end{array}$ & $\begin{array}{c}0.0239 \\
(1.40)\end{array}$ \\
\hline Firm Fixed Effects & Yes & Yes \\
\hline Day of Week Fixed Effects & No & Yes \\
\hline Constant & $\begin{array}{c}0.000141^{* * * *} \\
\quad(19.14)\end{array}$ & $\begin{array}{c}0.000143^{* * * *} \\
(15.31)\end{array}$ \\
\hline Observations & 17449 & 17449 \\
\hline
\end{tabular}

As for non-trading variance, cross-listing seems to have little effects. As shown in Table 7, the coefficient on the cross-listing dummy is not significant. Moreover, the persistence is also little influenced.

We conclude from the above that cross-listing induces reduction in trading volatility and overall volatility, but leaves non-trading volatility roughly unchanged. This fact is inconsistent with the public information hypothesis. Otherwise, if one believes that cross-listing will not change the information release custom of a firm, then there should be no significant change in both the overall volatility and trading volatility. If one believes that cross-listing does induce firms to report more in Japanese business hours, one should observe a significant increase in non-trading volatility. Neither is consistent with the data.

Our results are consistent with the joint hypothesis that international cross-listing reduces the amount of private information (Stulz [17], Coffee [6], Coffee [7], and King and 
Segal [13]) and that privately informed traders are mainly concentrated on the domestic market (Admati and Pfleiderer [1], Barclay, Litzenberger, and Warner [3], and Chowdhry and Nanda [5]). As exposed to increasing regulation requirements and a new jurisdiction system, cross-listing firms have to take some actions to reduce the amount of private information available to informed individuals. Since private information can only be incorporated into price via trading, less private information makes prices during trading hours less volatile. On the other hand, in Admati and Pfleiderer [1] setting, discretionary liquidity traders prefer to cluster their trades in the domestic market. The informed traders follow suit and there will be few informed traders active in the foreign market. Since privately informed traders are reluctant to move to the overseas market, the reduction on private information will have little effect on the non-trading volatility. As the trading volatility decreases while the non-trading volatility stays roughly the same, the overall volatility will decrease as observed.

Table 7. Cross-listing: Non-trading Variance

This table reports the regression results for non-trading variance before and after cross-listing. $D$ is the indicator for experiencing a cross-listing. Non-trading variance is as defined in Table 2. T statistics are in parentheses and *,**, *** indicate significance at $10 \%, 5 \%$, and $1 \%$ level respectively.

\begin{tabular}{lcc}
\hline \hline & $(1)$ & $(2)$ \\
& Non-trading variance & Non-trading variance \\
\hline D & 0.00000239 & 0.00000245 \\
Lag Non-trading Var & $(1.25)$ & $(1.28)$ \\
& $0.0638^{* * *}$ & $0.0642^{* * *}$ \\
D*Lag Non-trading Var & $(5.27)$ & $(5.30)$ \\
& 0.0137 & 0.0134 \\
Lag Trading Var & $(0.78)$ & $(0.76)$ \\
& $0.0143^{* * *}$ & $0.0144^{* * *}$ \\
D*Lag Trading Var & $(6.23)$ & $(6.30)$ \\
& 0.00324 & 0.00315 \\
Non-trading Var (Control) & $(0.74)$ & $(0.72)$ \\
& $0.0463^{* *}$ & $0.0462^{* *}$ \\
D*Non-trading Var (Control) & $(2.84)$ & $(2.83)$ \\
& -0.00341 & -0.00361 \\
Firm Fixed Effects & $(-0.25)$ & $(-0.27)$ \\
Day of Week Fixed Effects & Yes & Yes \\
Constant & No & Yes \\
& & \\
\hline Observations & $0.0000237^{* * *}$ & $0.0000260^{* * *}$ \\
\hline \hline
\end{tabular}

Our results are also consistent with the joint hypothesis that cross-listing will draw more investors' attention to the stock (Merton [15], King and Segal [13]) and that with more investors' attention, non-informed speculation traders would put less effort. With more investors' recognition, it turns to be harder for the stock to largely deviate from its fundamental. Therefore, there is fewer opportunity for non-informed speculators to trade in this stock. They may just leave it away, reducing the amount of noisy trading that generates noisy variance in the trading hours. Since the foreign market has small capitalization and volume, as stated by Barclay, Litzenberger, and Warner [3] who also focused on U.S. firms cross-listing in Japanese markets, whether noisy trading is increasing or decreasing abroad tends to have little impact on the non-trading volatility in the domestic market. Therefore, we then observe that trading volatility decreases after crosslisting while non-trading volatility remains similar. In total, overall volatility decreases.

Our current setting cannot distinguish which of the two effects above is the dominate one. We leave this for further research.

\subsection{International Cross-delisting}

Table 8 shows the simple two sample $\mathrm{T}$ test results for cross-delisting. All the overall variance, the trading variance and the non-trading variance seem to increase significantly after cross-delisting. In addition, this phenomenon is robust in most of the days of a week. Specifically, the overall variance increases from 0.0001549 (or equivalently $19.76 \%$ annual volatility) before cross-delisting to 0.0001793 (or equivalently $21.26 \%$ annual volatility) after cross-delisting, indicating a $15.75 \%$ growth. The trading variance increases from 0.0001282 (or equivalently $17.97 \%$ annual volatility) to 0.0001464 (or equivalently $19.21 \%$ annual volatility) which is a $14.20 \%$ growth.

One may have similar concerns on the macroeconomic factors as for the situation of cross-listing, as most crossdelisting cases in our sample happened during late 1990s (See Table 1). Hence, we also conduct the excess variance two sample $\mathrm{T}$ test on cross-delisting events. As shown in Table 9, adding comparable cannot remove the effects of crossdelisting. Still, the overall variance, trading variance and non-trading variance will increase significantly after the treatment.

But all results in Table 8 and Table 9 may be still driven by some firm idiosyncratic character that may not be able to be controlled by the comparable. We then also repeat the model based analysis for cross-delisting. The results are shown in Table 10, 11 and 12 .

It can be seen from Table 10 that after controlling the firm fixed effect and the comparable, cross-delisting still has a positive effect on overall variance, although only statistically significant under $10 \%$ significance level. But the point estimates still imply a $\sqrt{0.0000187 \times 252}=6.86 \%$ increase in overall annual volatility after cross-delisting. Just like what we observe in cross-listing cases, cross-delisting does not change the persistence structure as the interaction term between one-day lag overall volatility and the event dummy is not significant. Also, adding day of week controls will not affect the estimates to a considerable extent. 
Table 8. Daily Volatility before and after International Cross-delisting

This table reports the two-sample T test results that compare the variance before and after cross-delisting. Panel A, B, C are for the overall variance, trading variance, and non-trading variance respectively as defined in Table 2 . In each panel, we report the pooled results in column (1) and separate results for different day of week in following columns. T statistics are in parentheses and $*, * *, * * *$ indicate significance at $10 \%, 5 \%$, and $1 \%$ level respectively.

\begin{tabular}{|c|c|c|c|c|c|c|}
\hline \multicolumn{7}{|c|}{ Panel A: Overall Volatility } \\
\hline & (1) & (2) & (3) & (4) & (5) & (6) \\
\hline & All & Mon & Tue & Wed & Thr & Fri \\
\hline \multirow[t]{2}{*}{ Before-After } & $-0.0000244^{* * *}$ & $-0.0000243^{* * *}$ & $-0.0000262 * * *$ & $-0.0000164 * *$ & $-0.0000248 * * *$ & $-0.0000305^{* * *}$ \\
\hline & $(-7.34)$ & $(-3.06)$ & $(-3.57)$ & $(-2.24)$ & $(-3.33)$ & $(-4.31)$ \\
\hline \multirow[t]{4}{*}{$N$} & 19840 & 3746 & 4068 & 4071 & 3986 & 3969 \\
\hline & \multicolumn{6}{|c|}{ Panel B: Trading Volatility } \\
\hline & (1) & (2) & (3) & (4) & (5) & (6) \\
\hline & All & Mon & Tue & Wed & Thr & Fri \\
\hline \multirow[t]{2}{*}{ Before-After } & $-0.0000182 * * *$ & $-0.0000160 * *$ & $-0.0000191 * * *$ & $-0.0000180 * * *$ & $-0.0000172 * * *$ & $-0.0000210 * * *$ \\
\hline & $(-6.80)$ & $(-2.51)$ & $(-3.29)$ & $(-3.00)$ & $(-2.86)$ & $(-3.62)$ \\
\hline \multirow[t]{4}{*}{$N$} & 19859 & 3733 & 4071 & 4066 & 4001 & 3988 \\
\hline & \multicolumn{6}{|c|}{ Panel C: Non-trading Volatility } \\
\hline & (1) & (2) & (3) & (4) & (5) & (6) \\
\hline & All & Mon & Tue & Wed & Thr & Fri \\
\hline \multirow[t]{2}{*}{ Before-After } & $-0.00000350 * * *$ & $-0.00000518 * * *$ & $-0.00000377 * * *$ & $-0.00000390 * * *$ & -0.00000113 & $-0.00000365^{* *}$ \\
\hline & $(-5.58)$ & $(-3.42)$ & $(-2.81)$ & $(-2.84)$ & $(-0.83)$ & $(-2.55)$ \\
\hline$N$ & 19840 & 3742 & 4079 & 4086 & 4021 & 3912 \\
\hline
\end{tabular}

Table 9. Daily Excess Volatility before and after International Cross-delisting

This table reports the two-sample $\mathrm{T}$ test results that compare the excess variance (compared with the comparable) before and after cross-delisting. Panel A, B, C are for the overall variance, trading variance, and non-trading variance respectively as defined in Table 2. In each panel, we report the pooled results in column (1) and separate results for different day of week in following columns. T statistics are in parentheses and *,**,** indicate significance at $10 \%, 5 \%$, and $1 \%$ level respectively.

\begin{tabular}{lcccccc}
\hline \hline & \multicolumn{7}{c}{ Panel A: Overall Volatility } & & \\
\hline & $(1)$ & $(2)$ & $(3)$ & $(4)$ & $(5)$ & $(6)$ \\
& All & Mon & Tue & Wed & Thr & Fri \\
\hline Before-After & $-0.0000431^{* * *}$ & $-0.0000419^{* * *}$ & $-0.0000429^{* * *}$ & $-0.0000314^{* * *}$ & $-0.0000456^{* * *}$ & $-0.0000537^{* * *}$ \\
& $(-8.75)$ & $(-3.53)$ & $(-3.91)$ & $(-2.86)$ & $(-4.23)$ & $(-5.14)$ \\
\hline$N$ & 18992 & 3586 & 3906 & 3887 & 3812 & 3801 \\
\hline \hline
\end{tabular}

Panel B: Trading Volatility

\begin{tabular}{lcccccc}
\hline & $(1)$ & $(2)$ & $(3)$ & $(4)$ & $(5)$ & $(6)$ \\
& All & Mon & Tue & Wed & Thr & Fri \\
\hline Before-After & $-0.0000307^{* * *}$ & $-0.0000247^{* *}$ & $-0.0000221^{* *}$ & $-0.0000328^{* * *}$ & $-0.0000288^{* * *}$ & $-0.0000450^{* * *}$ \\
& $(-7.55)$ & $(-2.55)$ & $(-2.52)$ & $(-3.58)$ & $(-3.14)$ & $(-5.12)$ \\
\hline$N$ & 19001 & 3565 & 3904 & 3875 & 3820 & 3837 \\
\hline \hline
\end{tabular}

Panel C: Non-trading Volatility

\begin{tabular}{lcccccc}
\hline & $(1)$ & $(2)$ & $(3)$ & $(4)$ & $(5)$ & $(6)$ \\
& All & Mon & Tue & Wed & Thr & Fri \\
\hline Before-After & $-0.00000486^{* * *}$ & $-0.00000819^{* * *}$ & -0.00000300 & $-0.00000491^{*}$ & -0.00000162 & $-0.00000691^{* * *}$ \\
& $(-4.21)$ & $(-3.04)$ & $(-1.15)$ & $(-1.94)$ & $(-0.65)$ & $(-2.65)$ \\
\hline$N$ & 18948 & 3574 & 3903 & 3896 & 3842 & 3733 \\
\hline \hline
\end{tabular}


Table 10. Cross-delisting: Overall Variance

This table reports the regression results for overall variance before and after cross-delisting. $D$ is the indicator for experiencing a cross-delisting. Overall variance is defined in Table 2. T statistics are in parentheses and *,**, *** indicate significance at $10 \%, 5 \%$, and $1 \%$ level respectively.

\begin{tabular}{lcc}
\hline \hline & $(1)$ & $(2)$ \\
& Overall variance & Overall variance \\
\hline D & $0.0000187^{*}$ & $0.0000188^{*}$ \\
& $(1.92)$ & $(1.92)$ \\
Lag Overall Var & $0.0573^{* * *}$ & $0.0579^{* * *}$ \\
& $(5.81)$ & $(5.85)$ \\
D*Lag Overall Var & -0.0105 & -0.0107 \\
& $(-0.60)$ & $(-0.61)$ \\
Overall Var (Control) & $0.0527^{* *}$ & $0.0524^{* *}$ \\
& $(2.46)$ & $(2.45)$ \\
D*Overall Var (Control) & $0.0435^{* * *}$ & $0.0433^{* * *}$ \\
& $(2.89)$ & $(2.89)$ \\
Firm Fixed Effects & Yes & Yes \\
Day of Week Fixed Effects & No & Yes \\
Constant & & \\
& $0.000128^{* * *}$ & $0.000135^{* * *}$ \\
\hline Observations & $(19.97)$ & $(20.71)$ \\
\hline \hline
\end{tabular}

Table 11 shows how trading variance will change after cross-delisting. Basically, it also increases although only significant at $10 \%$ significance level. Specifically, crossdelisting will induce a $\sqrt{0.0000135 \times 252}=5.83 \%$ growth in trading volatility per annum. Again, the persistence structure is not influence by cross-delisting dramatically and adding day of week controls has little effects when firm fixed effects and comparables have already been controlled.

Table 12 shows that after controlling the firm fixed effect and the comparable firm, cross-delisting will not affect non-trading variance to a large extent, although the estimated coefficient is positive. Also, cross-delisting will not influence the persistence on how today's non-trading variance depends on yesterday's non-trading volatility and trading volatility.

We conclude from above that international cross-delisting increases both overall volatility and trading volatility, but leaves non-trading volatility roughly unchanged. This is just the opposite from what we observe in cross-listing. Therefore, one can reverse the rationale for cross-listing to explain the fact for cross-delisting. Specifically, the cross-delisting findings are also against the public information hypothesis. Otherwise, if cross-delisting will make the firm send less information in Japanese business hour,s the non-trading volatility should reduce. Or if cross-delisting does not change firm's information announcing custom, neither the overall volatility nor the trading volatility should differ.
Table 11. Cross-delisting: Trading Variance

This table reports the regression results for trading variance before and after cross-delisting. $D$ is the indicator for experiencing a cross-delisting. Trading variance is as defined in Table 2. T statistics are in parentheses and *,**, $* * *$ indicate significance at $10 \%, 5 \%$, and $1 \%$ level respectively.

\begin{tabular}{lcc}
\hline \hline & $(1)$ & $(2)$ \\
& Trading variance & Trading variance \\
\hline $\mathrm{D}$ & $\left(1.6000135^{*}\right.$ & $0.0000135^{*}$ \\
& $0.0534^{* * *}$ & $(1.67)$ \\
Lag Trading Var & $(4.36)$ & $0.0541^{* * *}$ \\
& -0.00661 & $(4.44)$ \\
D*Lag Trading Var & $(-0.34)$ & -0.00684 \\
& $0.244^{* * *}$ & $(-0.35)$ \\
Non-trading Var & $(5.98)$ & $0.244^{* * *}$ \\
& -0.0237 & $(5.94)$ \\
D*Non-trading Var & $(-0.32)$ & -0.0246 \\
& $0.0541^{* *}$ & $(-0.34)$ \\
Trading Var (Control) & $(2.64)$ & $0.0538^{* *}$ \\
& 0.0213 & $(2.63)$ \\
D*Trading Var (Control) & $(1.19)$ & 0.0210 \\
& & $(1.18)$ \\
Firm Fixed Effects & Yes & Yes \\
Day of Week Fixed Effects & No & Yes \\
Constant & & $(18.99)$ \\
\hline Observations & $(20.59)$ & 17527 \\
\hline \hline
\end{tabular}

But the findings are consistent with the private information hypothesis discussed above. Cross-delisting from a foreign market may help the firm get rid of the jurisdiction system and regulation requirments there. Hence more private information might be available around selected informed individuals. Those individuals incorporate their information during trading hours, leading to an increase in the trading volatility and overall volatility.

The results are also consistent with the noisy trading hypothesis discussed above. Cross-delisting may make, especially foreign, investors neglect the firm. As a result, there is a higher probablity for the firm's price to deviate from its fundamentals. If it were the case, non-informed speculators may step in so the volatility will increase during the trading hour and so is the overall volatility.

Again, our current setting can hardly distinguish these two effects. We leave this for further research. 
Table 12. Cross-delisting: Non-trading Variance

This table reports the regression results for non-trading variance before and after cross-delisting. $D$ is the indicator for experiencing a cross-delisting. Non-trading variance is as defined in Table 2. T statistics are in parentheses and *, $* *$, *** indicate significance at $10 \%, 5 \%$, and $1 \%$ level respectively.

\begin{tabular}{lcc}
\hline \hline & $(1)$ & $(2)$ \\
& Non-trading variance & Non-trading variance \\
\hline D & 0.00000201 & 0.00000201 \\
Lag Non-trading Var & $(1.41)$ & $(1.42)$ \\
& $0.0307^{* *}$ & $0.0304^{* *}$ \\
D*Lag Non-trading Var & $(2.53)$ & $(2.54)$ \\
& 0.00322 & 0.00364 \\
Lag Trading Var & $(0.20)$ & $(0.23)$ \\
& $0.00872^{* * *}$ & $0.00894^{* * *}$ \\
D*Lag Trading Var & $(2.48)$ & $(2.59)$ \\
& 0.00544 & 0.00529 \\
Non-trading Var (Control) & $(1.37)$ & $(1.35)$ \\
& $0.0541^{* * *}$ & $0.0537^{* * *}$ \\
D*Non-trading Var (Control) & $(3.03)$ & $(3.02)$ \\
Firm Fixed Effects & 0.00342 & $(0.29)$ \\
Day of Week Fixed Effects & $(0.26)$ & Yes \\
Constant & Yes & Yes \\
\hline \hline & No & $0.0000218^{* * *}$ \\
& $(23.36)$ & $(15.31)$ \\
\hline
\end{tabular}

\section{Conclusion}

We document the long-term effects on stock volatility of cross-listing and delisting. We find that cross-listing reduces the overall and trading volatility, while cross-delisting increases the overall and trading volatility. Both cross-listing and delisting leave the non-trading volatility roughly unchanged.

Our findings are consistent with the joint hypothesis that cross-listing (delisting) reduces (increases) the amount of private information and that informed traders are reluctant to trade abroad. Our findings are also consistent with the hypothesis that cross-listing (delisting) reduces (increases) the noisy trading conducted by non-informed speculators.

Our findings suggest that financial regulators may want to encourage domestic firms to dual list abroad to enhance informed trading, as a way to increase price discovery or to reduce uninformed speculations. Domestic investors may enjoy a lower trading-hour volatility together with a roughly unchanged non-trading-hour volatility. The impact of crosslisting on investor learning and asset return volatilities could be particularly relevant for markets dominated by noisy retail investors.

\section{References}

[1] Admati, Anat R., and Paul Pfleiderer, 1988, A Theory of Intraday Patterns: Volume and Price Variability, Review of Financial Studies 1, 3-40.

[2] Angelidis, Dimitrios, Athanasios Koulakiotis, Katerina Lyroudi, and Konstantinos Tolikas, 2009, The Impact of Foreign Cross-listings on Volatility Spillovers between Stock Markets: the Case of the Paris Stock Exchange, International Research Journal of Finance and Economics 25, 240-246.

[3] Barclay, Michael J., Robert H. Litzenberger, and Jerold B. Warner, 1990, Private Information, Trading Volume, and Stock-Return Variances, The Review of Financial Studies 3, 233-253.

[4] Bayar, Asli, and Zeynep Önder, 2005, Liquidity and Price Volatility of Cross-listed French Stocks, Applied Financial Economics 15, 1079-1094.

[5] Chowdhry, B., and V. Nanda, 1991, Multimarket Trading and Market Liquidity, Review of Financial Studies 4, 483511.

[6] Coffee, John C., 1999, The Future as History: The Prospects for Global Convergence in Corporate Governance and Its Implications, Northwestern University Law Review 93, 641-708.

[7] - 2002, Racing Towards the Top? The Impact of Cross-Listings and Stock Market Competition on International Corporate Goverance, Columbia Law Review 102, 1757-1831.

[8] Domowitz, Ian, Jack Glen, and Ananth Madhavan, 1998, International Cross-Listing and Order Flow Migration: Evidence from an Emerging Market, Journal of Finance 53, 2001-2027.

[9] Foerster, Stephen R., and G. Andrew Karolyi, 1999, The Effects of Market Segmentation and Investor Recognition on Asset Prices: Evidence from Foreign Stocks Listing in the United States, Journal of Finance 54, 981-1013.

[10] French, Kenneth R., and Richard Roll, 1986, Stock Return Variances: The Arrival of Information and the Reaction of Traders, Journal of Financial Economics 17, 526.

[11] Howe, John S., and Jeff Madura, 1990, The Impact of International Listings on Risk Implications for Capital Market Integration, Journal of Banking and Finance 14, 1133-1142.

[12] _ and Alan Tucker, 1993, International Listings and Risk, Journal of International Money and Finance 12, 99-110. 
[13] King, Michael R., and Dan Segal, 2009, The LongTerm Effects of Cross-Listing, Investor Recognition, and Ownership Structure on Valuation, The Review of Financial Studies 22, 2393-2421.

[14] Kyle, Albert, 1985, Continuous Auctions and Insider Trading, Econometrica 53, 1315-1335.

[15] Merton, Robert C., 1987, A Simple Model of Capital Market Equilibrium with Incomplete Information, Journal of Finance 42, 483-510.
[16] Roosenboom, Peter, and Mathijs A. van Dijk, 2009, The Market Reaction to Cross-listing: Does the Destination Market Matter?, Journal of Banking and Finance 33, 1898-1908.

[17] Stulz, René M., 1999, Globalization, Corporate Finance, and Cost of Capital, Journal of Applied Corporate Finance 26, 3-28. 